\title{
Kierkegaard, el autor sin público Notas sobre la lectura a propósito de To Tidsaldre
}

\section{Kierkegaard, the Author without an Audience. To Tidsaldre and Some Notes on Reading}

\author{
JUAN EVARISTO VALLS BOIX \\ Universidad de Barcelona
}

Recibido: 28/10/2016 Aceptado:02/05/2017

\section{RESUMEN}

El propósito de este estudio consiste en mostrar la crítica de Kierkegaard a la metafísica de la lectura a través de su problematización de la noción de autor y su revisión de la noción de público en su obra Dos épocas. Una recensión literaria. Para ello, se rechazará la interpretación habitual de esta obra, basada en la distinción público/privado, y se valorará la propuesta de Kierkegaard mediante las nociones de cuerpo e intimidad. Ello implicará una redefinición del lenguaje desde el secreto y el silencio, y apuntará hacia una relación compleja entre la literatura, el cuerpo, la subjetividad y la religión.

PALABRAS CLAVE

KIERKEGAARD, AUTOR, PÚBLICO, CUERPO, INTIMIDAD

\section{ABSTRACT}

The aim of this paper is to show Kierkegaard's critique to the metaphysics of reading. It will focus the problematization of the notions of author and public in Kierkegaard's Two Ages. A Litterary Review. The paper will refuse the usual interpretation of this work, based in the 
distinction public/private, and it will offer an alternative view with concepts such as body and intimacy. This will imply a redefinition of language from concepts such as secret and silence, and it will point towards a complex relationship between literature, body, subjectivity and religion.

KEYWORDS

KIERKEGAARD, AUTOR, PUBLIC, BODY, INTIMACY

Sí creo que el poeta debe luchar antes que nada por hacerse con una personalidad versada hasta conseguirlo y solo esta personalidad, una vez muerta y transfigurada $-\mathrm{y}$ no aquella poligonal, terrenal, palpable-, debe y puede producir.

Søren Kierkegaard, De los papeles de alguien que todavía vive

\section{INTRODUCCIÓN}

En FEBRERo DE 1846, KieRKegaARd COQUeteó en su diario con la idea de dejar de ser escritor para convertirse en un pastor rural en la península de Jutlandia. ${ }^{1}$ Lo único que escribía en ese momento era una pequeña reseña literaria, que suponía un final en su carrera como autor. Poco después saldrían a la luz su Post Scriptum a las Migajas filosóficas y la susodicha reseña, que había alcanzado, paradójicamente, el tamaño de un libro. El texto daba cuenta de la novela Dos épocas (To Tidsaldre) de Thomasine GyllembourgEhrensvärd, ${ }^{2}$ un libro que fue publicado por el hijo de la autora, el escritor danés Johan Ludwig Heiberg, en 1845. La resistencia de Kierkegaard a escribir junto con su pasión por la escritura habían generado un fruto anómalo: dos obras sin autor, o dos obras antiautoriales. De un lado, un post-scriptum, una apostilla o el resto de una obra anterior -resto excesivo de una extensión hasta cuatro veces superior-: un mero añadido -por lo demás, no el anexo de

$1 S K S$ 18, 278. Se trata de la edición danesa de la obra completa de Kierkegaard, seguida del volumen y el número de página (véase bibliografía).

2 El título de la publicación, aparecida en 1846 como libro, será En literair Anmeldelse. To Tidsaldre, Novelle af Forfatteren til «en Hverdagshistorie», udgiven af J. L. Heiberg. [«Una recensión literaria. Dos Épocas.» Novela del autor de Una historia cotidiana, editada por J. L. Heiberg]. En castellano solo está disponible una breve parte de la recensión: Kierkegaard 2012b (en adelante EP). Se ha consultado también, por ello, la edición inglesa de los Hong: Kierkegaard 1987. Cabe además añadir que la novela Dos épocas se publicó como anónima, así como la anterior obra de Gyllembourg-Ehrensvärd, Una historia cotidiana. 
un sólido tratado, sino de unas fragmentarias «migajas de filosofía»- firmado bajo el pseudónimo Johannes Climacus, nombre que además alude al término filosófico desechable por excelencia: la escalera. ${ }^{3}$ De otro lado, un mero comentario, una recensión de prensa a la obra de otro autor, además anónimo, a la que se subordina y solo con motivo de la cual desarrolla sus ideas. Si cuando quiso dejar de escribir, Kierkegaard escribió una reseña, era porque entendía en este gesto una anulación de la autoría: «de esta forma, seguiría evitando convertirme en autor». ${ }^{4}$ También este escrito, por descontado, es muy extenso: casi tanto como la novela reseñada. La preocupación por no decir y dejar de hablar no se aferra al mutismo, sino a la proliferación de una escritura otra.

Y en la parte final de esta reseña, con epígrafe «La época presente» (Nutiden) Kierkegaard emprende una ponzoñosa crítica contra un elemento que es supuestamente indispensable para todo autor que se precie: el público. Estos actos contradictorios (escribir como un no-autor, conjurar al público consustancial a toda autoría) no solo reflejan el temor a los peligros de la escritura, ${ }^{5}$ sino que también apunta a su prevención: esbozan una manera otra de escribir y de leer. ¿Pero quién es el que lee cuando no hay público?

Tradicionalmente, la crítica de Kierkegaard al concepto de público en «La época presente» se ha comprendido, desde el énfasis del término kierkegaardiano «nivelación», como una prefiguración del fenómeno de masas de la era contemporánea. Siguiendo planteamientos como los de Heidegger, ${ }^{6}$ Kierkegaard denunciaría la experiencia alienante que desdibuja los contornos de la subjetividad individual, lo que supone la evaporación de la responsabilidad y la disolución, por tanto, de la ética. De esta manera, se ha entendido a Kierkegaard como un precedente de esa distinción público/ privado en la que el individuo solitario, recogido sobre sí mismo y autor de una personalidad consistente, puede sustraerse a la indiferenciación de la multitud y practicar una crítica lúcida que la masa, evadida por los encantos del consumo y el espectáculo, es incapaz ya de hacer.

No obstante, me distanciaré de esta interpretación, de una vigencia dudosa, para enlazar el problema del público con las estrategias antiautoriales de Kierkegaard y las implicaciones lingüísticas de las mismas, que serán la

3 Sobre la etimología de este pseudónimo, véase Conant 1997, pp. 1-35, así como 1996, pp. 249-331.

4 SKS 18, 279.

5 Véase Rocca 2009, pp. 571-583. Pese a que me distanciaré de las conclusiones de Ettore Rocca, su trabajo analiza con precisión los extractos de los escritos personales de Kierkegaard en que se rechaza la idea de continuar escribiendo.

6 Heidegger 2012, §27. Encontramos esta posición, por ejemplo, en Conway 1999, p. 30, Marsh 1984, pp. 155-174 o Hoberman 1984, pp. 223-258. 
base para una concepción particular de la lectura -alejada de la aristocracia lectora del individuo aislado-. Así, el propósito de este trabajo será exponer el concepto de público que Kierkegaard desarrolla en su recensión literaria, pero de una forma alternativa a aquella. Si el público es, efectivamente, «una monstruosa nada», ${ }^{7}$ su opuesto no es un individuo particular aislado o singular, puesto que «ningún hombre particular [Ingen enkelt Mand] podrá detener la abstracción de la nivelación, porque esta es negativamente superior y la época de los héroes ha pasado». ${ }^{8}$ La concreción del individuo que busca Kierkegaard como su único lector no consiste en una individualidad aislada. Consiste, antes bien, en leer a través del cuerpo 9 .

\section{El ESTANCAMIENTO EN LA REFLEXIÓN}

Pero debemos antes rehacer la línea argumental de Kierkegaard. Este califica su época como la «época de la reflexión», ${ }^{10}$ una época esencialmente desapasionada donde los excesos de la abstracción de cuño hegeliano han descendido del cielo de las teorías al plano de la existencia: ya no hay acción ni decisión, solo una sucesión degenerada de pretextos morales, un vago ejercicio reiterativo de la prudencia y la sensatez basados en la eliminación de cualquier disyuntiva ante la que posicionarse y, a través de la elección, realizarse. La época de la reflexión es una época de charla, ${ }^{11}$ pues se ha suspendido la alternativa entre hablar -exponerse, manifestarse- y callar omitir, reservar-, y prolifera un vago intermedio sintético; es una época de superficialidad y deseo de exhibición, pues se ha abolido la tensión entre la reserva y la revelación de sí mediante la abstracción; es, además, una época de informidad, o de información, que ha superado en el lenguaje la disyuntiva y la tensión entre forma y contenido, es decir, que ha perdido el carácter alusivo y polívoco de las palabras. ${ }^{12}$ Se trata de una época de anonimidad, donde se

7 EP 67/ SKS 8, 86.

8 EP 65/ SKS 8, 83.

9 El propósito de pensar la cuestión del autor junto con la, por así decir, cosificación del lenguaje y la nivelación del público distancia este trabajo de otros análisis, como el excelente Jaarsmat 2013, que sitúa a Kierkegaard en el debate con la teoría crítica contemporánea y la biopolítica. Sus múltiples aciertos no colman, a mi entender, la ausencia de un cuestionamiento de los elementos paratextuales y literarios de la reseña.

10 EP 43 / SKS 8, 68.

11 Caputo lo explica con relativo detenimiento en Caputo 2007, pp. 86-87ss. Por otro lado, Fenves aborda el concepto de charla en otra dirección (1993, pp. 191-243).

12 Kierkegaard expone sistemáticamente estas disyunciones a lo largo de EP 75-83/ SKS 8, 92-99. 
habla anónimamente y no se alcanza a formar «un discurso personal, como aquel que puede llevar a cabo el más simple de los hombres». Es decir,

ya no hay nadie que hable, pero una reflexión objetiva va estableciendo un algo atmosférico; un ruido de la abstracción que vuelve superfluo el hablar humano $[\ldots]$ En Alemania ya se tiene manuales para los amantes. ${ }^{13}$

Kierkegaard ofrece, para abordar la crítica de su época, un análisis preliminar sobre las transformaciones de su lenguaje. El lenguaje en la época de la reflexión se ha despersonalizado, ha perdido su anclaje en la realidad en tanto que esta es un espacio de tensión, de contradicción y de irresolución, ${ }^{14}$ y se ha instalado en el terreno de la abstracción, donde ha perdido su carácter connotativo, su versatilidad al ser dicho por alguien -por eso es anónimo, porque se habla como si el lenguaje fuera estrictamente abstracto, idéntico a sí mismo, únicamente denotativo, sin importar quién lo hable. Por ello el lenguaje siempre dice lo mismo y se agota en las palabras, ha perdido su silencio y sus facetas múltiples; se entrega de una vez, en una sola lectura. No hay nadie en concreto que lo hable, al sujeto concreto le ha relegado el sujeto teórico de la abstracción, válido para todos y en todo momento, perfectamente identificable, plenamente exhibido. Por ello se escriben manuales para amantes: porque se ama anónimamente, o nadie ama, o siempre ama y habla una misma identidad indiferenciada, reconocible, clasificable. Kierkegaard lo denomina «informidad» [Formløshed], y Benjamin calificaba este discurso como «información»: el lenguaje que pretende «transmitir el puro 'en sí' de la cosa». ${ }^{15}$

Es este lenguaje informativo e idéntico a sí mismo el que impone el cálculo de la racionalidad y la estadística de la sensatez en el terreno de la ética. La acción, que no es sino la experiencia de la tensión de opciones contrarias, ha abandonado la existencia para tener lugar únicamente en el pensamiento como una operación lógica: «La sensatez ha llegado a estar tan extendida, que se han

13 EP 83 / SKS 8, 98

14 Sàez Tajafuerce 1999, p. 58.

15 Benjamin 2009, p. 40. Benjamin oponía el lenguaje de la información al de la narración, que, también en consonancia con Kierkegaard, «sumerge la cosa en la vida del narrador para sacarla de ahí a continuación» (Íbid.). Así, no es de extrañar que tanto en esta reseña, como en su crítica a la novela de Andersen Apenas un músico, Kierkegaard aludiera a la pertinencia de una visión de la vida como cimiento de la literatura, lo que por lo demás no tiene nada que ver con el raigambre de la literatura en la vida privada del autor, pues «tan pronto como el productivo artista entrega en la obra su propia realidad, su facticidad, deja de ser realmente productivo» (EP 76 / SKS 8, 94). Arraigar la literatura en una visión de la vida consiste en conferirle el carácter ambiguo, indeterminado, paradójico o irresoluble de la realidad. A propósito de la informidad del discurso o del lenguaje como información, véase Pardo 1996, p. 89 ss. 
transformado las tareas en una actuación irreal, y la realidad en un teatro». ${ }^{16} \mathrm{La}$ época de la reflexión ha atribuido, a través de la ponderación de este lenguaje de lo abstracto, al pensamiento y al razonamiento un valor tan excesivo, que su culminación en la realidad no tiene ningún valor: los principios y los razonamientos generales de este lenguaje de lo idéntico convierten la acción en una mera representación del principio. La reflexión, la sensatez, la prudencia, ofrecen siempre al individuo una evasión de la acción: «La reflexión está en condiciones de dar una nueva interpretación y permitirnos huir hacia alguna parte», de modo que «ni para el individuo ni para la generación hay tarea o esfuerzo más difícil que escapar de las tentaciones de la reflexión». ${ }^{17}$ Todo puede resolverse «sin jamás actuar». ${ }^{18}$

Ello no debe llevar a comprender a Kierkegaard como un pensador irracional o a su postura como un decisionismo. Su crítica se centra en el exceso o estancamiento de la reflexión, en el aplazamiento indefinido de la acción:

La reflexión no es lo perverso, sino que la regresión es producida por la condición de reflexión y el estancamiento en la reflexión: estos son los abusos y corrupciones que transforman los prerrequisitos en evasiones. ${ }^{19}$

La reflexión no basta para conformar la ética, que solo se culmina a través de la acción y la decisión como un momento de pasión en que la cadena deliberativa se ve interrumpida. Los principios morales que orientan la acción en un plano abstracto, deben suspenderse -que no eliminarse- en el momento de decidir, pues decidir no consiste en resolver el carácter contradictorio de la realidad, sino en abrazar uno de sus extremos y sacrificar los otros. No basta actuar por principio, sino actuar, por uno mismo, como sí mismo, como nadie más que sí mismo; más allá de todo principio:

todo se permite por principio, y se evita toda responsabilidad [...] El actuar por principio [...] falsifica la acción moral convirtiéndola en abstracción. ${ }^{20}$

Esta facilidad de ser una cosa y luego otra según el principio a que uno se adscriba genera una ambigüedad moral en la existencia: el individuo se ve privado de una posición determinada, ha perdido la capacidad de decisión porque «la disyuntiva cualitativa de las cualidades es debilitada 
por una reflexión roedora». ${ }^{21}$ Ello también está relacionado con la pérdida del principio de no contradicción en favor de la síntesis de ascendencia hegeliana: la cancelación de este principio en la existencia solo puede generar esa ambigüedad del individuo que retarda continuamente el momento de posicionarse en la disyuntiva gracias al estancamiento en la reflexión. Este abandono de la posición existencial y el olvido de la acción mediante el exceso de la reflexión genera una nueva ilusión: en lugar de establecer una relación de interioridad con la existencia -esto es, una relación apasionada-, el individuo es en la relación siempre una tercera parte: se vuelve espectador u observador de la realidad: «El ciudadano ya no es parte de la relación, sino un espectador que estudia el problema de la relación». ${ }^{22}$

Esta dinámica genera lo que Kierkegaard llama «nivelación», que no es sino una operación matemática que uniformiza a los individuos valiéndose de su recurso a la reflexión. ${ }^{23}$ Al igual que antes el lenguaje había perdido su relieve y su forma, el individuo ya no se concibe relacionalmente: ha perdido, como el lenguaje, la versatilidad de la connotación, ha sustituido su intimidad y sus reservas, como el lenguaje ha sustituido sus silencios y connotaciones, por el deseo de exhibición, por la univocidad y la estricta identidad a sí mismo -la creencia en una plena manifestabilidad que genera la pobreza de la información.

La nivelación genera una igualdad que elimina todo carácter y prima la cantidad de individuos sobre la cualidad característica: toma de los individuos su carácter contable, su dimensión abstracta: se sirve de la ilusión según la que ahora solo se comprenden entre ellos como sujetos de reflexión y solo actúan por principios. El individuo ya no se tiene a sí mismo, solo pertenece a la abstracción, donde es identificable, calculable y uniforme. Se ha instalado en la ilusión que le garantiza que la existencia puede resolverse mediante la dialéctica.

¿Ello qué implica? Si el estancamiento en la reflexión convertía al lenguaje en información, este exceso hace, de la subjetividad, una personalidad unificada, entera y terminada, idéntica a sí misma, por tanto «irreal.» ${ }^{24}$ Como observa Hannay, mientras que del hegelianismo se desprende una concepción de la subjetividad como personalidad unificada y sólida, el Johannes Climacus del Post Scriptum, justo antes de Una recensión literaria, sostiene que el individuo carece de recursos para unificarse a sí mismo, pues

21 EP 52, SKS 8, 75.

22 EP 52-55 / SKS 8, 74-76.

23 Para una revisión detallada del concepto de nivelación, véase, entre muchos otros, Westfall 2007, p. 200 ss, Caputo 2007, pp. 85-86, o Hannay 1999, pp. 71-79.

24 EP $68 /$ SKS 8, 87. 
está «dialécticamente consolidado» en la fe. ${ }^{25} \mathrm{El}$ individuo de la época de la reflexión, que se quiere unívoco, que se contempla a sí mismo como a un espectador, se reduce a una personalidad plenamente decible, a una vida privada. La nivelación supone la uniformización de todos los individuos, que se vuelven identificables en tanto que personalidades de vida privada, una vida que se vehicula, transparente, en la charla, que ha abolido la posibilidad de callar y guardar para sí. Personalidades cuyo relato es la información, rica en chascarrillos y fruslerías, de la prensa soez. Como apunta Llevadot, «la privacidad no se opone a la publicidad, sino que ambas pertenecen al mismo ámbito conceptual». ${ }^{26}$

No obstante, la nivelación se realiza siempre mediante un tercero. Este tercero es algo abstracto, es una nada, o mejor, consiste en la suma de individuos «en aquellos momentos en que no son nada». ${ }^{27}$ Kierkegaard lo llama «el público».

\section{EL PÚBLICO ES LO INCORPÓREO}

El público es una pura abstracción, el conjunto de la sociedad cuyos individuos solo se comprenden como un solo actor común y universal: son variaciones de este, se adscriben a él en cuanto números, des-relacionados con su realidad y con otros individuos. Es el gran nivelador, pues cada vez que se alude a él, que se actúa por él, crece sin empacho, pudiendo ser tanto

25 Hannay 1999, p. 76. De ahí que Johannes Climacus apunte en el Post Scriptum que la subjetividad es la verdad y, a su vez, la no verdad; esto es, que la subjetividad difiere de sí misma y está en íntima contradicción consigo misma, como la realidad. $C f$. Kierkegaard 2010, p. 191 ss / SKS 7, 173 ss. A este respecto, el estudio de Lappano sobre la concepción kierkegaardiana de la prensa y el periodismo, a pesar de su claridad expositiva y las sugerentes relaciones establecidas entre la teoría crítica y la recensión, acaba por afirmar que «la diferencia está entre relacionarse con una abstracción personal y relacionarse con una particularidad personal» (2014, p. 794), aserto que le permite asumir sin empacho la crítica adorniana a la individualidad de Kierkegaard como interioridad burguesa (2014, p. 792). Nuestra posición, próxima a la observación de Hannay, encuentra en la subjetividad kierkegaardiana antes una contradicción, una relación, una intimidad, que aquella particularidad. Por ello mismo, también nos distanciamos de las reflexiones sobre la identidad existencial que establece Mehl (2005), quien considera que «el ideal kierkegaardiano de personalidad» consiste en florecer como un yo espiritual autotranscendente [flourishing as a self-transcending spiritual self] (p. 160), en una suerte de revisión existencialista-constructivista que no escapa a las críticas que hiciera Adorno sobre la espiritualidad kierkegaardiana (Adorno 2006, pp. 13ss).

26 Llevadot 2012, p. 9. Matas Pons llega a conclusiones muy similares desde un recorrido por Rousseau y la Teoría Crítica que le lleva a hablar de «consumo de la identidad», un consumo que efectivamente solo es posible tras la positivación de la misma en una privacidad a través de una «identificación estética» $(2015,641-641)$.

27 EP 70 / SKS 8, 89. 
el principio que legitima una acción como el que la condena. Este gran ente borroso y vago no solo surge del estancamiento de la reflexión y del desapasionamiento de la época, sino también de otro elemento abstractivo: la prensa, esto es, como ya indicamos, el lenguaje de la información. ${ }^{28}$

La prensa genera esa opinión pública que no es de nadie y es de todos, que tan pronto dice una cosa como dice la otra. Su contenido es la vaguedad superficial de la charla, que aborda y entrega con el máximo interés las vidas privadas de esos sujetos idénticos, que informa sobre cualquier cosa, que lo traduce todo en información e inunda el lenguaje con «un mar de irrelevancia y banalidad». ${ }^{29}$ Puesto que la prensa despoja al individuo de toda realidad al tratarlo como sujeto abstracto calculable, este pierde su interioridad, su capacidad de diferir de sí mismo, de ser diferente. Al perder su interioridad, pierde su silencio, pues «el silencio es la interioridad», lo que «hace evidente el vacío», ${ }^{30}$ que la prensa, con su habladuría constante y su afán de ventas, teme y quiere traducir como vida privada de la que informa como primicia. ¿Y qué quiere decir perder el silencio? Precisamente la capacidad de hablar y producir, ${ }^{31}$ esto es, la posibilidad de connotar el lenguaje, de guardar para sí, reservarse y no decir a través del lenguaje, de hacer del lenguaje un espacio tan rico y polívoco como la realidad, con tantos intersticios de silencio como taras de sinrazón alberga aquella. Supone perder el riesgo de la decisión y la experiencia de la contradicción, pues «la expresión absoluta del silencio es que la idealidad contiene la posibilidad cualitativamente opuesta» de la que se ha elegido cuando se habla o se actúa. ${ }^{32}$ Una vez la subjetividad se ha reducido a una personalidad unificada, con una identidad controlable y testable, tan unívoca y denotativa como el lenguaje de la abstracción, se traduce como vida privada en la información que la prensa difunde: «el público es lo público, pero interesado en lo más estrictamente privado». ${ }^{33}$ No obstante, ya no se

28 Lappano recoge diversos momentos de la crítica kierkegaardiana de la prensa, esparcida por sus diarios, en 2014, pp. 783-785.

29 Pardo 1996, p. 105.

30 Ibid.

31 EP $76 /$ SKS 8, 94.

32 Ibid.

33 EP 78 / SKS 8, 95. De este modo se hace patente que la crítica de Kierkegaard no se dirige únicamente al público, sino a la distinción binaria público/privado: su diagnóstico sobre la nivelación conjura tanto la masa uniformada de individuos como el individuo único, exclusivo y bien definido. Lamenta, pues, la pérdida o el olvido de lo que en el individuo está siempre excediendo la individualidad, esto es, lo que en la subjetividad hay de no-idéntico, de diferente, de silencio, en fin, de íntimo. En este sentido, las lúcidas reflexiones de Caputo pierden su vigor al identificar la subjetividad compleja -paradójica, vulnerable- de Kierkegaard con esa interioridad romántica que constituye uno de los últimos capítulos de la conciencia moderna. Así lo indica Caputo: «cualquier versión de posmodernismo sería crítica con la 'interioridad' absoluta 
es capaz de alcanzar lo íntimo, es decir, de conquistar el silencio gracias al que se puede hablar, del mismo modo que el lenguaje informativo carece de connotatividad, de su posibilidad de decir varias cosas a la vez, y se consume en una sola lectura.

El problema del discurso y de la reflexión es que no pueden guardar silencio, no pueden callar. Quizá pueda estructurarse, delimitarse, dividirse, pero no guardar silencio: su propósito consiste antes en saturar de sentido la realidad y en no abandonar la charla, que en asomarse al vacío del silencio que supondría detener la reflexión en ese instante de locura que es la decisión y la vuelta a la realidad. De esta forma, el público no es tanto una multitud de hombres, la masa anónima que despersonaliza y escandaliza a la interioridad burguesa $^{34}$ del idealista subjetivo, a la subjetividad individual que el burgués gestiona como su propiedad privada - este burgués que administra su relato privado ya forma parte de la charla pública-: «El público no es un pueblo, ni una generación, ni una época, ni una congregación, ni una asociación, ni tales personas determinadas [...] nadie de los que pertenecen a un público se encuentra realmente vinculado a algo». ${ }^{35} \mathrm{El}$ público es lo desvinculado, lo desrelacionado, lo irreal, lo abstracto: combina la apoteosis de la información con la apoteosis de la personalidad como vida privada. Es lo desvinculado, pero no es una masa o una turba de hombres:

El público es un concepto que ni siquiera podría haber existido en la Antigüedad, porque incluso el pueblo se veía obligado a aparecer en masse in corpore en la situación de acción. [...] Solo cuando se carece de una fuerte vida comunal que dé cuerpo a la concreción, entonces la prensa creará este público abstracto, compuesto de individuos irreales [uvirkelige] que jamás se unen o podrán ser unidos en la simultaneidad de una situación u organización y que, sin embargo, se sostienen como un todo. [...] cuando la época es desapasionada, reflexiva y destructora de todo lo concreto, el público viene a ser el que lo cubre todo. ${ }^{36}$

El público, entonces, es lo incorpóreo. Por ello solo puede ser charla, pues solo un cuerpo puede guardar silencio. Por ello es lo desvinculado, porque solo

[thoroughgoing inwardness'] de la subjetividad kierkegaardiana, que los críticos postmodernos tratan como uno de los fatalmente defectuosos axiomas de la modernidad.» (Caputo 2007, p. 88). Nuestro propósito es, antes bien, mostrar cómo la subjetividad kierkegaardiana ya participa de ese gesto postmoderno (o «antimoderno», véase Stokes y Buben 2011, pp. 22, 33-34, 281 o Rossatti 2016) y se dibuja como una figura vulnerable, fragmentaria.

34 Buck-Morss 1975, p. 499.

35 EP $70 /$ SKS 8, 79.

36 EP 68 / SKS 8, 87. Subrayados propios, traducción modificada. 
un cuerpo puede ser atravesado por la experiencia. Por ello es irresponsable, porque solo un cuerpo se decide y sacrifica. Por eso nunca puede alcanzar lo íntimo, pues solo el cuerpo es único e inapropiable, como la intimidad.

De esta forma, a través del público no se instala tanto la manida dicotomía público/privado, cuanto la diferencia entre el cuerpo y la abstracción, ${ }^{37}$ el cuerpo como diferencia y reserva -y ello implica vinculación, decisión- ante la abstracción como discurso de lo idéntico y lo homogéneo. El individuo, la interioridad, son ese espacio de silencio que solo tiene lugar en un cuerpo, cuando este decide callar o hablar y se posiciona en la existencia como experiencia de sí. La interioridad no es traducible en una vida privada, ni puede tener público: es la resistencia del sujeto a traducirse por entero, lo que se refleja en el lenguaje cuando este ya no es unívoco y dice siempre algo de más y algo de menos, lo que le hace diferir. Así, «la interioridad kierkegaardiana no es, pues, lo inefable, aquello mudo sin posibilidad de ser expresado en el lenguaje, sino la posibilidad de que el individuo no lo diga todo, que sea capaz de guardar el secreto que podría comunicar, $[. .$.$] de resistirse a [...] construir$ nuestro yo normalizado». ${ }^{38}$ Como bien indica también Krimmse, al individuo no se le exige ninguna forma de heroísmo o liderazgo - que formaría más bien parte del deseo de exhibición que promueve la superficialidad de la prensa-, sino, como expresión de «la contrapartida dialéctica de la plaga moderna de publicidad y anonimidad, este individuo singular debe ser irreconocible antes que un líder carismático y visible, e incluso en su autocomprensión privada debe entender que está sin autoridad». ${ }^{39}$

Con ello, esa interioridad, el cuerpo, en definitiva, es aquello que nunca puede apropiarse, que está abierto al porvenir, que no puede explicitarse plenamente. El cuerpo es lo que se sustrae a la reflexión. Para ello, Kierkegaard

37 ¿Supone esto entonces sustituir la dicotomía público/privado por la dicotomía sensible/ abstracto? Nada más lejos de mi intención. Al comprender la noción kierkegaardiana de público como lo incorpóreo, no lamento «la inmediatez perdida de la presencia colectiva [corporate presence]», como indica George Pattison (1999a, p. 16). No me refiero al cuerpo en sentido de una presencia, sino al contrario: el cuerpo como lo no-presente, lo que no es reconocible, lo que no se expone plenamente, sino que guarda siempre para sí una reserva, un resto que no exhibe, y ello justamente porque, en primer lugar, está ante una alteridad que le configura y que desconoce-como se verá-, y en segundo lugar, porque está siempre por acabar, tendido al porvenir, y nunca completo o idéntico a sí mismo (el cuerpo no es identificable), como también se señalará a propósito de la idea de lo cómico.

38 Llevadot 2012, p. 15

39 Kirmmse 1999, p. 198. 
se sirve del concepto de lo cómico, que califica como lo inesperado e imprevisto y opone al control de la reflexión:

\begin{abstract}
¿Pero qué es más singular que lo chistoso, lo cual es más singular e incluso más sorprendente que el primer brote de la primavera y que el primer verdor de la pradera? Porque incluso si la primavera llegara tras previo acuerdo, seguiría siendo primavera, pero un chiste tras previo acuerdo es algo repugnante. Supongamos, pues, que [...] se llega tan lejos que lo chistoso, ese acontecimiento divino cuando llega, ese obsequio como saludo de Dios desde el enigmático origen de lo inexplicable, de modo que ni el más chistoso que haya vivido se atreve a decir 'mañana', sino que devotamente dice 'si Dios quiere'-, supongamos que lo chistoso fuera transformado en su más banal contrario, en una trivial necesidad de la vida, $[\ldots]$ en una lucrativa industria el fabricar [...] nuevos chistes: ¡qué terrible epigrama para una época chistosa! ${ }^{40}$
\end{abstract}

Si el público es lo incorpóreo, es porque, en tanto que hijo de la época de la reflexión, ha sustituido lo enigmático, inexplicable, imprevisto e impensado de la intimidad del sujeto -su singularidad, su diferencia en tanto que relacionado con la alteridad absoluta- por una «trivial necesidad de la vida», esto es, por las naderías de la privacidad. Si el lenguaje de la información que se despliega en la prensa es el correlato de este público incorpóreo, monstruosa nada de la reflexión, es porque es un lenguaje sin singularidad, homogéneo e idéntico, plenamente expuesto y controlado, sin los intersticios de silencio por los que se filtraba lo cómico, lo inesperado, y la subjetividad.

Así, si la época es cómica, ${ }^{41}$ es porque, pese a su empeño en valorar lo cómico, su estancamiento en la abstracción le impide alcanzar la chispa de lo inesperado e imprevisible que caracteriza lo cómico, y además, el cuerpo: «La época presente es la de las anticipaciones». ${ }^{42} \mathrm{Si}$ la prensa y la publicidad son el discurso propio de la época dominada por la reflexión, es porque implican el olvido del cuerpo y la abstracción del lector, que pasa a ser considerado como una estadística, como un número, como el público en general, pues todo el mundo lee igual. «La contemporaneidad con personas reales, cuando cada una de ellas es algo, en un instante real y una situación real, fortalece al individuo. Pero la existencia de un público no crea ni una situación ni una comunidad». ${ }^{43}$ El público está ligado al texto plano y unívoco que es la información, y a la carencia de una experiencia del cuerpo, un texto que guarda silencio.

40 EP 48-49 / SKS 8, 71-72. Traducción modificada.

41 Ibid.

42 EP 43 / SKS 8, 68.

43 EP $68 /$ SKS 8, 87. 
De esta forma, al relacionar inextricablemente el público al lenguaje de la prensa, y el individuo singular como cuerpo a un lenguaje de reservas y silencios, Kierkegaard establece una vinculación fuerte entre la subjetividad y el texto en que se despliega. La subjetividad se configura como una estructura textual, adquiere una forma literaria. La literatura, en fin, se convierte en el espacio de la subjetividad. ${ }^{44}$

\section{KIERKEGAARD, EL AUTOR SIN PÚBLICO}

Nadie se hace una idea clara del hambre intensa de univocidad que es el máximo afecto de todo público. Un centro, un dirigente, una consigna. [...] El que un autor empiece a despertar 'interés', significa tan solo que se empieza a buscar su fórmula, su expresión más unívoca y primitiva.

Walter Benjamin, Denkbilder

Quizá se comprendan mejor ahora algunos de los esfuerzos de Kierkegaard por dejar de ser un autor. Sabía que, pese a la enormidad que suponía el público, y pese a su capacidad de legitimar cualquier cosa, «vale menos que una sola persona real». ${ }^{45}$ Sabía que si se dirigía a una abstracción, a una uniformidad reflexiva, él mismo acabaría nivelado, dejándose llevar por la opinión pública, los debates público-privados y la charlatanería: entraría en el juego de la autoridad del mensaje unívoco, del autor-divulgador de su vida privada y del culto al público. Sabía que estaría siendo tentado por la irrealidad de la reflexión, tan sencilla e indolente. Por ello, probablemente, escribe la siguiente nota: «por fortuna, como autor jamás he buscado tener público, sino que alegremente me he conformado con 'aquel individuo'. Producto de esta restricción me he vuelto casi proverbial». ${ }^{46}$

Dirigirse a ese individuo, y nunca a un público, no es entonces otra cosa que escribir para un cuerpo. E implica comprender que solo un cuerpo puede leer: solo se puede comprender a través de la experiencia: «El individuo que lee no es un público». ${ }^{47}$ Por ello, la reseña que escribiera para la novela Dos épocas contiene un prefacio en el que indica: «Esta reseña no es para lectores estéticos y críticos de periódico, sino para criaturas racionales que se toman tiempo y tienen la paciencia para leer un pequeño libro, aunque no

44 Sàez Tajafuerce 1999, pp. 59-60.

45 EP 70/ SKS 8, 89.

46 EP $71 / S K S$ 8, 90.

47 EP 68 / SKS 88. Pero ello no porque el público sea una masa iletrada, a diferencia del intelectual aislado y culto, sino justamente, como se ha mostrado, porque leer implica re-leer, y por ello la conciencia del carácter insaturable del texto. 
necesariamente este». ${ }^{48} \mathrm{Si}$ solo un cuerpo puede leer, es porque a través de la lectura se establece una relación, un vínculo, aunque siempre abierto, con lo leído: se lee en silencio, no mediante la habladuría. Se lee y se escribe sin público.

Escribir para un cuerpo: escribir para quien sabe guardar silencio. Escribir desde un cuerpo: escribir desde el silencio, desde la reserva o la resistencia a la plena exposición de la abstracción:

el silencio, con el cual [el artista] protege su propia realidad, es precisamente la condición para ganar la idealidad. Porque un autor puede tener una personalidad privada [private Personlighed] como todo otro hombre, pero esta debe ser su $\alpha \delta v \tau o v$. Y tal y como se cierra la entrada a una casa poniendo dos soldados con bayonetas cruzadas, así el equilibrio de la idealidad, a través de la cruz dialéctica de los opuestos cualitativos, enseña a mantener cerrada esa puerta y no permitir ninguna entrada. ${ }^{49}$

La posición de quien escribe sin ser autor, sin querer decir, permanece secreta, sagrada, intocable. Se escribe desde un espacio que se reserva, que no se puede mostrar, desde una «posición espectral que da lugar a una estrategia discursiva mediante la cual se posibilita e imposibilita a la vez la enunciación unívoca, es decir, la enunciación que remite a una sola voz y a un solo sentido». ${ }^{50}$ Kierkegaard, como un escritor de existencia «postautorial», ${ }^{51}$ borra de la página el rastro de sí mismo, se desapropia del texto al no vincularlo a ninguna personalidad privada contrastable y se sustrae a la lógica del público y el discurso de la prensa. Los lectores sabrán qué encontrarán en su escritura, pero en tanto autor no será sino un lugar hueco de emisión, un espacio inidentificable. Así como el lector situado se oponía al público y a la homogeneidad de la identificación, y de este modo permanecía siempre irreconocible, en sus críticas al concepto de público y al lenguaje de la prensa que lo posibilita, Kierkegaard emplea cuantas estrategias están a su disposición para desaparecer y borrar su nombre del texto que escribe: sea escribiendo sin autoridad, sea mediante pseudónimos, o sea como mero

48 El prefacio está ausente en la edición española. Véase $S K S$ 8, 9, o la version en inglés (Kierkegaard 1987, p. 5).

49 EP 76 / SKS 8, 93-4. Escribió Kierkegaard algo similar en 1843, poco después de la aparición de $O$ lo uno o lo otro, en un artículo titulado «¿Quién es el autor de $O$ lo uno o lo otro?» y publicado en Fcedrelandet, donde sentencia que la búsqueda del autor es una pérdida de tiempo, y que sin esta personalidad el lector puede adentrarse en el libro sin ser molestado o distraído (SKS 4, 49 ss). Para otros detalles al respecto, véase Watkin 1993, p. 31.

50 Sàez Tajafuerce 2015, pp. 172-3. Cortes Favis aborda cuestiones similares al pensar a Kierkegaard como un poeta-dialéctico (2009, pp. 567-8).

51 Conway 1999, p. 23. 
reseñador literario. No en vano afirmaba que prefería aproximarse a sus obras como lector y no como autor, esto es, desde la distancia que le aliviara de la identificación completa, de la apropiación. Como apunta Pardo, «de mí mismo solo sé en la distancia y gracias a la distancia». ${ }^{52}$

De este modo, Kierkegaard se presenta como autor de un texto periodístico dirigiéndose no a un público, sino a «ese individuo». Subvierte así la lógica de la prensa, reintroduciendo en ella la realidad del individuo frente a la abstracción incorpórea del público: quiebra el género desde dentro del mismo. A través de tal gesto, se busca la construcción de una literatura no-abstracta, una literatura del cuerpo. Una escritura que exhorte al lector a salir de la reflexión -o que no lo instale en ella- y le inste a decidir, a existir desde el silencio que muestra el vacío. Esta literatura entra en oposición con la opinión pública de la prensa, esa información caduca, plenamente significativa -por abstracta- que hacía del lector un número. Ante ella, se muestra de nuevo como el cuerpo de un texto: anclado en la realidad, dándose infinitamente pero guardando un silencio, una reserva, un carácter íntimo inapropiable: «el silencio es también condición para la conversación culta entre un hombre y otro». ${ }^{53}$ La ilegibilidad, pues, permite la lectura, diferencia la lectura. ${ }^{54}$

\section{Punto CONClusivo}

Hemos mostrado una posible lectura del texto La época presente en que la distinción privado/público es relevada por una reflexión sobre la intimidad del cuerpo y los peligros del exceso de la abstracción. El sujeto

52 Pardo 1996, p. 161

53 EP 76 / SKS 8, 94.

54 Lisse 1996, p. 200. En este sentido, la encendida crítica de Poole (2002) contra «los posmodernos» (p. 395) por sus apropiaciones de Kierkegaard no repara con suficiente detenimiento en las implicaciones de la différance en la lectura, que Lisse apunta con precisión a través de la aporía de la (i)legibilidad (véase también Lisse 1992, p. 135ss. o, en un recorrido más general, Lisse 2001). Los comentarios de Poole reenvían a una metafísica de la lectura en que hay una obra sustancial -aunque compleja, de lectura indecidible, etc.- producida por un autor sustancial -aunque sin autoridad, etc.- cuyo sentido, por muy enmarañado que esté por una retórica, ha de ser encontrado por un lector igualmente sólido y definido. Indica Poole «el prestigio de los ataques postestructuralistas y posmoderno hacia 'el yo' ha sido tan irrefutable por tanto tiempo que es casi una locura sugerir que podríamos empezar de nuevo, y observar el yo como una realidad que habitamos y de la que somos responsables. Si pudiéramos separar la propia sabiduría de Kierkegaard de todos los trucos de artificio literario en su escritura propia del s. XIX, seríamos mucho más provechosos para él. Pero ello requiere coraje [...] Hay un significado que encontrar, y ese significado no será encontrado por un gesto de virtuosismo intelectual, sino por un acto de coraje» (pp. 441-442). Nuestro planteamiento se basa en que ese coraje no se dirige hacia un significado cautivo, sino que es una pasión por el secreto del texto (Derrida 1993, pp. 68ss). 
desvela su estructura textual tanto en el estancamiento de la reflexión, donde el lenguaje unívoco, denotativo y explícito de la prensa y la habladuría público-privada tiene como correlato la nada del público, homogénea, indiferenciada y abstractiva, como en los esfuerzos de Kierkegaard por criticar tal estancamiento, donde la legitimación de la corporalidad de la subjetividad -entendida como vinculación, decisión y apertura cómica a lo imprevisible e impensable-, que hacía del individuo algo diferente de sí, no identificable, era indisociable de un lenguaje de carácter literario, connotativo, que hablaba sin decir y que guardaba para sí intersticios de silencio. En su esfuerzo por dejar de ser un autor, Kierkegaard desactiva la primera dinámica -una dinámica de la personalidad privada y de la información- para introducir en su interior la segunda, en la que como autor ocupa una posición espectral.

Solo una cosa no se ha mencionado: que la única forma que Kierkegaard admite de detener la nivelación es mediante la conquista individual de la «intrepidez de lo religioso.» ${ }^{55}$ Que la abstracción de la nivelación solo se produce «al olvidar la separación de la interioridad religiosa.» ${ }^{56}$ Quedan así ligados, de un lado, la abstracción, la charla de la prensa, la sensatez de la reflexión y la personalidad privada, y de otro, curiosamente, el cuerpo, el silencio de la literatura, la religión y la individualidad irreconocible. Deberá todavía emprenderse un camino de exploración hacia este vínculo entre la religión y la literatura, entre la religión y el cuerpo ${ }^{57}$. Un vínculo que solo

55 EP $62 / \operatorname{SKS} 8,83$.

$56 \mathrm{Ibid}$. Subrayado mío.

57 Apunto tan solo la fecundidad del pensamiento de Kierkegaard a propósito del llamado «retour du religieux» ( $c f$. Derrida 2000) o la a/teología de la deconstrucción ( $C f$. Taylor 1984, Caputo 2001, etc.). En la obra del danés puede rastrearse el propósito de articular una noción de religión que no sea reducible a una institución o a un credo, esto es, el intento de concebir una «religión sin religión» ( $c f$. Caputo 1997, Derrida 1999): se trata de no identificar la fe cristiana con la cristiandad, sino de preservarla en su exceso constitutivo. El interés de la religiosidad kierkegaardiana como marco para pensar cuestiones como la subjetividad y la literatura subyace en su esfuerzo por abordarlas desde nociones aporéticas o incalculables tales como la alteridad (Dios como lo absolutamente diferente), la fe (como un salto infinito), la decisión (como un instante de locura) y, como se ha mostrado, el secreto (decir sin decir, ironizar). Son, en suma, diversas instancias que interrumpen y trastornan la estabilidad de un orden y suponen una exigencia para un nuevo pensamiento, un pensamiento otro. Así, Caputo apunta que «es en virtud de este axioma de imposibilidad que espero mostrar que, propiamente entendida, la deconstrucción corresponde a la categoría de 'lo religioso', tal y como es descrita por los pseudónimos [kierkegaardianos]. Ambas constituyen contravenciones análogas del buen sentido y el negocio como lo usual del mundo, lo que tanto Derrida como de Silentio consideran o llaman la 'economía' del mundo, que disturban en nombre de una más alta locura» (2002, p. 4). Abunda Caputo en On Religion: «la tarea esencial es llevar la fe cristiana más allá de la Razón, el Sistema y la Verdad filosófica. Es con Kierkegaard, diría, que el 'post' de lo que llamamos pos-moderno o post-secular o post- 
podrá pensarse, me temo, desde el silencio ${ }^{58}$.

\section{REFERENCIAS BIBLIOGRÁFICAS}

ADORNO, Th. W. 2006: Kierkegaard. Construcción de lo estético, trad. de Joaquín Chamorro Mielke. Madrid: Akal.

BENJAMIN, W. 2012: Denkbilder, trad. de Jorge Navarro Pérez. Madrid: Abada Editores.

. 2009: «El narrador. Consideraciones sobre la obra de Nikolái Léskov» en Obras completas, libro II/vol. 2, trad. Jorge Navarro Pérez, pp. 41-68. Madrid: Abada Editores.

BERTHOLD, D. 2006: «A Question of Style: Hegel and Kierkegaard on Language, Communication, and the Ethics of Authorship», Clio 35 (2), pp. 179-200 . 2005: «Kierkegaard's Seductions: The Ethics of Authorship», MLN 120 (5), pp. 1044-1065.

CAPUTO, J. D. 2007: How to read Kierkegaard?. London: W. W. Norton \& Company . 2002. «Looking the Impossible in the Eye: Kierkegaard, Derrida, and the Repetition of Religion», Kierkegaard Studies Yearbook 2002 (1), pp. 1-25. 2001. On religion. London: Routledge.

. 1997: The Prayers and Tears of Jacques Derrida. Religion without Religion. Bloomington: Indiana University Press.

CAPUTO, J. D., DOOLEY, M. y SCANLON, M. J. 2001: Questioning God. Bloomington: Indiana University Press.

CONANT, J. 1997: «Kierkegaard's Postscript and Wittgenstein's Tractatus: Teaching How to Pass from Disguised to Patent Nonsense», Wittgenstein Studien 4 (2), pp. 1-35.

. 1996: «Putting Two and Two Together: Kierkegaard, Wittgenstein and the Point of View for Their Work as Authors», en Phillips (ed.), The Grammar of Religious Belief. Nueva York: St. Martin's Press, pp. 249-331.

CONWAY, D. W. 1999: «Modest Expectations: Kierkegaard's Reflections on the Present Age», Kierkegaard Studies Yearbook 1999 21-49.

CORTES FAVIS, M. 2009: «The Concept of Writing, with Continual Reference to 'Kierkegaard'», The European Legacy: Toward New Paradigms, 14 (5), pp. 561572, DOI: $10.1080 / 10848770903128687$.

COWARD, H. y FOSHAY, T. (eds.) 1992: Derrida and Negative Theology. Nueva York: State University of New York Press.

metafísico aparece por primera vez». (2001, pp. 50-1). Otros comentaristas como Manning 2004 o Kangas 1998 se sitúan en esta perspectiva.

58 Remitimos, para continuar a través de este silencio, a Rocca 2000, Strawser 2006, Rogan 1992, Garff 1996 y Taylor 1981, entre tantos otros. 
DERRIDA, J. 2005: Force de Loi. París: Galilée. . 2000 : Foi et Savoir, suivi de Le Siècle et le Pardon. Paris : Seuil. 1999: Donner la mort. París: Galilée.

. 1993: Passions. París : Galilée.

DERRIDA, J. y FERRARIS, M. 1997: Il gusto del segreto. Roma: Laterza.

FENVES, P. 1993: "Chatter». Language and History in Kierkegaard. Stanford: Stanford University Press.

GARFF, J. 2003: “'What did I find? Not my I' On Kierkegaard's Journals and the Pseudonymous Autobiography», Kierkegaard Yearbook 2003, pp. 110-124.

. 1999: “'You Await a Tyrant whereas I Await a Martyr': One Aporia and its Biographical Implications in A Literary Review,» Kierkegaard Studies Yearbook 1999, pp. 130-148.

. 1996: «Johannes de silentio: Rethorician of Silence», Kierkegaard Studies Yearbook 1996, pp. 186-210.

GONZÁLEZ, D. 1999: «Kierkegaard et la question de la conceptualité», Kierkegaardina 20, pp. 83-95.

HANNAY, A. 1999: «Kierkegaard Levelling and the Review», Kierkegaard Studies Yearbook 1999, pp. 71-95.

HEIDEGGER, M. 2009: Ser y tiempo, trad. de Jorge Eduardo Rivera. Madrid: Trotta.

HOBERMAN, J. M. 1984: «Kierkegaard's Two Ages and Heidegger's Critique of Modernity» en Perkins (ed.), International Kierkegaard Commentary: Two Ages. Macon, GA: Mercer University Press, pp. 223-258.

JAARSMAT, A. S. 2013: «Kierkegaard, Biopolitics and Critique in the Present Age», The European Legacy. Toward New Paradigms 18 (7), pp. 850-866, http://dx.doi. org/10.1080/10848770.2013.839492

KANGAS, D. 1998: «Kierkegaard, the Apophatic Theologian», Enrahonar. An International Journal of Theoretical and Practical Reason 29, pp. 119-123

KIERKEGAARD, S. 2012a: Temor y temblor, trad. Vicente Simón Merchan. Madrid, Alianza.

. 2012b: La época presente, trad. de Manfred Svensson. Madrid: Trotta.

. 2011: Post Scriptum no cientifico y definitivo a «Migajas filosóficas», trad. de Javier Teira y Nekane Legarreta. Madrid: Sígueme.

. 2010: Søren Kierkegaards Skrifter. Elektronisk version 1.5, ed. Søren Kierkegaard Forskningscenteret, sks.dk, Copenhague.

. 2009a: The Point of View, Kierkegaard's Writings, XXII, trad. H. y E. Hong. Princeton: Princeton University Press.

. 2009b: Repetition and Philosophical Crumbs, trad. de Edward F. Mooney. Oxford: Oxford University Press.

. 2000: De los papeles de alguien que todavía vive. Sobre el concepto de ironía, 
Escritos de Søren Kierkegaard, vol. 1, trad. de Darío González y Begonya Sàez Tajafuerce. Madrid: Trotta.

. 1987: Two Ages: The Age of Revolution and The Present Age. A Literary Review, ed. y trans. de Howard V. y Edna H. Hong. Nueva Jersey: Princeton University Press.

KIRMMSE, B. H. 1999: «Apocalypse Then: Kierkegaard's A Literary Review,» Kierkegaard Studies Yearbook 1999, pp. 182-203.

LAPPANO, D. 2014: «A Coiled Spring: Kierkegaard on the Press, the Public, and a Crisis of Communication», Heythrop Journal 55, pp. 783-798.

LIPPITT, J. y PATTISON, G. (eds.) 2013: The Oxford Handbook of Kierkegaard. Oxford: Oxford University Press.

LISSE, M. (ed.) 1996 : Passions de la littérature. Avec Jacques Derrida. París: Galilée.

. 1992: «Donner à lire», en Rabaté, Jean-Michel y Wetzel, Michael (eds.) : L'éthique du don. Jacques Derrida et la pensée du don. Colloque de Royaumont décembre 1990. París : Métailié-Transition, pp. 133-151

. 2001: L'expérience de la lecture, 2 vols. París : Galilée

LLEVADOT, L. 2012: «La intimitat: de la privacitat del jo a l'escriptura de si», Comprendre 14 (1) 5-19.

. 2008: «Kierkegaard y la cuestión del lenguaje». Daimon. Revista de Filosofía 43, pp. 93-101.

MANNING, E. 2004: «The Possibility of a World without Absolute Truth: Caputo and Kierkegaard on Faith and Religious Belief», Diaporia. Undergraduate Journal for Philosophy and Humanities 1(2), pp. 4-11

MARSH, J. L. 1984: «Marx and Kierkegaard on Alienation,» en Perkins (ed.), International Kierkegaard Commentary: Two Ages. Macon, GA: Mercer University Press, pp. 155-174.

MARTINEZ, R. 2003: «Figuring Kierkegaard's Relgious Individual», Laval théologique et philosophique 59 (3), pp. 521-533

MATAS PONS, À. 2015: «Falseamiento y consumo de la identidad, de Rousseau a Adorno», Isegoría 53, pp. 631-646. doi: 10.3989/isegoria.2015.053.09

MEHL, P. 2005: «In the Twilight of Modernity: Kierkegaard and Contemporary Reflections on Existential Identity», en Thinking through Kierkegaard. Existential Identity in a Pluralistic World. Illinois: University of Illinois Press, pp. 119-162

PARDO, J. L. 1996: La intimidad. Valencia: Pre-textos.

PATTISON, G. 1999a: «The Present Age: the Age of the City», Kierkegaard Studies Yearbook 1999, pp. 1-20. . 1999b: Poor Paris! : Kierkegaard's Critique of the Spectacular City. Berlin. De Gruyter.

PERARNAU VIDAL, D. y PARCERO OUBIÑA, Ó. 2009: «Spain: The Old 
and New Kierkegaard. Reception in Spain,» en Stewart (ed.), Kierkegaard's International Reception, Tome II, Southern, Central and Eastern Europe, a su vez en Kierkegaard Research: Sources, Reception and Resources, vol. 8, pp. 17 80. Aldershot: Ashgate.

POOLE. R. 2002: «Towards a Theory of Responsible Reading: How to Read and Why», Kierkegaard Studies Yearbook 2002, pp. 395-442

ROCCA, E. 2009: «La tâche de ne pas écrire. L'écriture comme non-art », Revue des sciences philosophiques et théologiques 93 (3), pp. 571-83.

. 2000: «Søren Kierkegaard and Silence», en HOUE, P., MARINO, G. D., y HAKON ROSSEL, S. (ds.): Anthropology and Authority. Essays on Søren Kierkegaard. Amsterdam: Rodopi, pp. 77-83.

ROGAN, J. 1992: «Keeping Silent through Speaking», en PATTISON, G. (ed.), Kierkegaard on Art and Communication. New York: St. Martin's Press, pp. 8899.

ROSSATTI, G. G. 2016: «Kierkegaard as an Antimodern Moralist: Re-Thinking 'Socio-Political' Categories in Recent Kierkegaard Scholarship», Kierkegaard Studies Yearbook 2016 (1) 51-74. doi:10.1515/kierke-2016-0106

SÀEZ TAJAFUERCE, B. 2015: «Kierkegaard y la crítica literaria: la prosa de Andersen», en González, Llevadot y Sàez Tajafuerce (eds.), Kierkegaard y las artes. Pensar la creación. Barcelona: Editorial UOC, pp. 171-186.

. 1999: «A Literary Review: A Rhetorical Experiment or 'Watchman, Hallo!'», Kierkegaard Studies Yearbook 1999, pp. 50-70.

STOKES, P. \& BUBEN, A. 2011: Kierkegaard and Death. Bloomington: Indiana University Press.

STRAWSER, M. 2006: «Gifts of Silence from Kierkegaard and Derrida», Soundings 89 (1-2), pp. 55-72.

TAYLOR, M. C. 1994: «Denegating God», Critical Inquiry 20/4, pp. 592-610.

. 1984: Erring. A Postmodern A/Theology. Chicago: University of Chicago Press. . 1981: «Sounds of Silence», Kierkegaard's Fear and Trembling. Critical Appraisals. Alabama: The University of Alabama Press, pp. 152-165.

WATKIN, J. 1993: «The Journals and the Works of 1843 with Particular Reference to Either/Or», Tópicos 5, pp. 19-51.

WESTFALL, J. 2007: The Kierkegaardian author, authorship and performance in Kierkegaard's literary and dramatic criticism. Berlín y New York: De Gruyter.

JuAn Evaristo Valls Boix es investigador predoctoral en el Departamento de Filosofía de la Universidad de Barcelona.

Líneas de Investigación:

Filosofía y literatura; Estética y política; Deconstrucción; Kierkegaard 
Publicaciones recientes:

2018: Giorgio Agamben. Politica sense obra. Barcelona: Gedisa

2017: "The Art of Writing Posthumous Papers'. Kierkegaard and the Spectral Audience», Avant: Journal of Philosophical-Interdisciplinary Vanguard VIII (2) 51-62.

Correo electrónico: valls-boix.j.e@ub.edu 